\title{
From Crime Scene Investigation to Toxicological Sampling: Forensic Approach to Volatile Substance Related Deaths
}

\author{
Straccamore $\mathbf{M}^{1 *}$, Petrasso PEY ${ }^{1}$, Umani Ronchi F ${ }^{1}$, Cappelletti $S^{1,2}$, Bottoni \\ $\mathrm{E}^{1}$ and Ciallella $\mathrm{C}^{1}$ \\ ${ }^{1}$ Department of Anatomical, Histological, Forensic Medicine and Orthopedic Sciences, \\ University of Rome, Italy \\ ${ }^{2}$ State Police Health Service Department, University of Rome, Italy
}

\section{Review Article \\ Volume 6 Issue 1}

Received Date: December 28, 2020

Published Date: January 18, 2021

DOI: $10.23880 /$ ijfsc- 16000218

*Corresponding author: Marco Straccamore, Section of Legal Medicine, Department of Anatomical, Histological, Forensic Medicine and Orthopedic Sciences, “Sapienza” University of Rome, Viale Regina Elena, 33600161 Rome, Italy, ORCiD 0000-0002-8957-2376; Email: marco.straccamore@uniroma1.it

\section{Abstract}

The ready availability of volatile substances makes their abuse frequent, and especially widespread among adolescents and young-adults, with significant rates of morbidity and mortality.

Even if this phenomenon has been described since 1960s, the abuse of volatile substances in forensic context is still a matter of debate. Scientific papers describe materials and procedures for sampling volatile substances when performing post mortem examination. However, proposed techniques involve the use of specific - and sometimes expensive - gas tightening materials that are not always available, whereas rapid identification of deaths related to volatile substance might be very important for the success of the whole investigation. This type of deaths could be mistaken for juvenile sudden deaths. Therefore, it is very important to search and collect all useful information, either form the crime scene or the forensic autopsy. In our work, we discuss the main pathophysiological mechanisms involved in deaths. In previous forensic papers, such mechanisms were considered less important than toxicological findings.

Keywords: Autopsy Procedure; Crime Scene Investigation; Forensic Pathology; Forensic Toxicology; Sudden Sniffing Death Syndrome; Volatile Substance Related Deaths

Abbreviations: CFC: Chlorofluorocarbons; HCFCs: Hydrochlorofluorocarbons; VSRD: Volatile Substance Related Deaths; VSA: Volatile Substance Abuse; EMCDDA: European Monitoring Centre for Drugs and Drug Addiction.

\section{Introduction}

In a work based on 110 deaths occurred in the USA during 1960 s, Bass described a "sudden sniffing death syndrome" among teenagers that misused chlorofluorocarbons (CFC), which in most of the cases had been misinterpreted as plastic-bag suffocation [1].

In the following years, the number of volatile substance related deaths (VSRDs) increased dramatically, with toxicologists and forensic pathologist reporting many fatal accidents involving hydrocarbons such as methane, butane, toluene and others. Subsequently, poisoning from new substances was also reported, while at the same time the abuse of CFC to "get high" decreased [2-6]. 


\section{International Journal of Forensic Sciences}

Volatile substance abuse (VSA) is defined by the European Monitoring Centre for Drugs and Drug Addiction (EMCDDA) as "the deliberate inhalation of volatile compounds to produce psychoactive effects" [7]. Terms such as "glue sniffing" and "solvent abuse" have been used previously to define VSA but are now regarded as inadequate descriptions of the range of substances abused and their consumption.

The volatile products are often legal, unexpansive, and relatively easy to obtain in a legal way on the market. In the past, socially and economically depressed teenagers presented higher rate of VSA consumption. Today, VSA represents a widespread problem, especially among adolescents and young-adults - in many countries second only to the use of cannabis - with significant rates of morbidity and mortality $[8,9]$.

In Great Britain, where a national register of VSRDs is active, 834 cases between 2001 and 2016 were reported. In particular, the mortality rate remained similar throughout the period, with 1 VSA-related death per million population in 2016, or 64 VSRDs (over $80 \%$ of these VSRDs were male subjects) [10].

The assumption of volatile substances can be performed in several ways, namely (i) by inhaling a substance directly from the product container ("sniffing" or "snorting"), (ii) placing some cloth soaked in the substance over the nose and mouth and inhaling ("huffing"), (iii) pouring a small amount of volatile substance into a paper or a plastic bag and breathing the fumes ("bagging"), or (iv) compressed gas dusters or nitrate canisters may be discharged directly into the mouth and inhaled ("dusting") [11].

There are various inhalants with different ingredients that can be misused (see Table 1).

\begin{tabular}{|c|c|c|}
\hline Category & Chemicals & Source \\
\hline \multirow{5}{*}{$\begin{array}{l}\text { Aliphatic and } \\
\text { Aromatic } \\
\text { Hydrocarbons }\end{array}$} & Butane, Propane & Hair spray, air fresheners, deodorants \\
\hline & Gasoline, Propane, Benzene, Butane & Fuels including cigarette lighter \\
\hline & Toluene, Hexane, Acetone, Ethyl Acetate & $\begin{array}{l}\text { Paint/polish removers, paint thinners, felt-tip } \\
\text { markers, correction fluids, glues and rubber cements }\end{array}$ \\
\hline & Benzene, Xylene & Varnishes, lacquers, resins, lacquer thinners \\
\hline & Dimethyl Ether, & Computer/electronic cleaning spray (duster) \\
\hline $\begin{array}{l}\text { Halogenated } \\
\text { Hydrocarbons }\end{array}$ & $\begin{array}{l}\text { 1,1-Difluoroethane, Tetrachloroethane, } \\
\text { Tetrafluoroethane, Tetrachloromethane, } \\
\text { Trichloromethane, Trichloroethane, } \\
\text { Tetrachloroethylene, Trichloroethylene, Metilene } \\
\text { Chloride }\end{array}$ & $\begin{array}{l}\text { Computer duster, propellant, refrigerant, solvent, } \\
\text { adhesives, degreaser, spot remover, typewriter or ink } \\
\text { correction fluid, dry cleaning solvent }\end{array}$ \\
\hline Anesthetics & $\begin{array}{l}\text { Chloroform, Ether, Nitrous Oxide, Halothane, } \\
\text { Ethyl Chloride, Diethyl Ether, Enflurane }\end{array}$ & $\begin{array}{c}\text { Laboratory anesthetic, dentist's office, whipped } \\
\text { cream dispensers }\end{array}$ \\
\hline $\begin{array}{l}\text { Volatile Alkyl } \\
\text { Nitrites }\end{array}$ & $\begin{array}{l}\text { Amyl Nitrites Butyl Nitrites Cyclohexyl Nitrite } \\
\text { Isopropyl Nitrite Other Nitrites }\end{array}$ & $\begin{array}{l}\text { Angina medications, air freshener, video recorder } \\
\text { head cleaner, synthesized products, popper }\end{array}$ \\
\hline
\end{tabular}

Table 1: Categories, examples and chemicals present in commonly abused inhalant.

In italics CFC (chlorofluorocarbons) which have been removed from the market.

The substances usually found in medical anesthetic gases are nitrous oxide, chloroform, ether and helium. Adhesives and spray paints, which often contain toluene, xylene, hexane and/or benzene, are products which can be misused easily. Amyl nitrite and butyl nitrite are both still available as solvents for video head cleaning, or can be packaged in small bottles called "poppers".

Other easily obtainable substances include (i) gasoline/ butane lighter refills, (ii) small cartridges of nitrous oxide (mainly used to dispense whipped cream), (iii) solvents such as acetone, acrylic nail remover, nail polish remover, mothballs, and mineral spirits, (iv) methanol from carburetor cleaners, and $(\mathrm{v})$ refrigerants from air conditioning units or from refill canisters.

Liquefied propane and butane are commercially available for cooking in pressurized tanks (LPG, Liquefied Petroleum Gas).

CFCs are chemical compounds containing chlorine, fluorine and carbon, used as aerosol propellants, refrigerating agents and also in the preparation of foamed plastics. 


\section{International Journal of Forensic Sciences}

However, since they were found contributing for the ozone layer reduction in the stratosphere, international agreements have banned their production and use (Montreal Protocol, 1987, extended to hydrochlorofluorocarbons - HCFCs - in 2007). The application of international agreements has made it necessary to replace these products. For aerosol packaging, light hydrocarbons (like butane, isobutane, pentane, and isopentane) have been introduced however, they create serious problems due to their high flammability [12].

Acute toxic effects of these substances include confusion, headache, diplopia, weakness, nausea/vomiting, dizziness, euphoria, hallucinations, convulsions, coma, cardiac arrhythmias, respiratory depression and death. It has been reported that butane is more toxic than propane, due to its greater anesthetizing effect.

VSRDs may be accidental or intentional, involving a variety of materials under a range of circumstances, as previous explained. For example, gas cylinders are more often used to suicide, as a large amount of butane is required. Some cases have been described as fatal intoxication during an autoerotic behavior, during which inhalation of gases (anesthetic agents, propane and cooking gas) and the wrapping of the head in a plastic bag is used to produce cerebral asphyxia and hypercapnia to get enhanced sexual pleasure [13-16]. In Italy, one of the most common forms of VRSD is described in prison population, by sniffing gas from camping refill cylinders, which can be used in jail [17-19].

\section{Volatile Substances Related Deaths}

\section{VSRD: Surveys at Crime Scene Investigation}

Although VSRDs are well known in forensic literature, deaths associated with VSA are in practice not always recognized or appropriately studied. Moreover, some VSRDs may be confused with unexplained sudden deaths, especially when forensic autopsy and toxicological analysis are inaccurate, or have not been performed at all.

Crime scene investigation may provide useful information regarding the presence of materials and objects such as plastic bags or tins, used to contain the volatile substance sniffed. Paint, glue, or typewriter correction fluid may be found on victims' hands or near the body. Forensic pathologist should be very careful in searching and identifying these objects on the crime scene, which may otherwise appear "neutral".

Witnesses - possibly themselves VSAs - may have deliberately concealed evidence cleaning up the scene before the arrival of police officers or emergency operators. In this case, the true circumstances of the death might be discovered only through extensive investigations and a long time after the autopsy is performed [20].

If the body has been moved from the place where the volatile substance was consumed, or otherwise the subject or others have concealed relevant objects, the body inspection is unlikely to show any relevant information of VSA. In these cases, one may be able to detect a strong smell on clothes and skin - the smell can be fruity (in case of solvent), or sweetish (in case of chloroform or other hydrocarbons). By the time the autopsy is performed, the smell of volatile substances may be lost.

After prolonged VSAs, physical evidence as "glue sniffer's rash" could be observed almost always- this is a characteristic popular eruption around the nose and mouth caused by the act of holding a bag against the lower face and the irritating action of the solvent. In repeated cases, we could also find ulceration of oral and nasal mucosa, sometimes infected or scratched, becoming crusted [21].

Rash's development depends both by the inhaled substance and the method of consumption. Therefore, the absence of a rash should not be considered as an exclusion criterion of VRSD.

The container could produce a semi-circular impression on the skin of the median lower face (perioral zone and chin's protuberance) if it is pressed against the mouth and nose just before death, see Figure 1 [22].

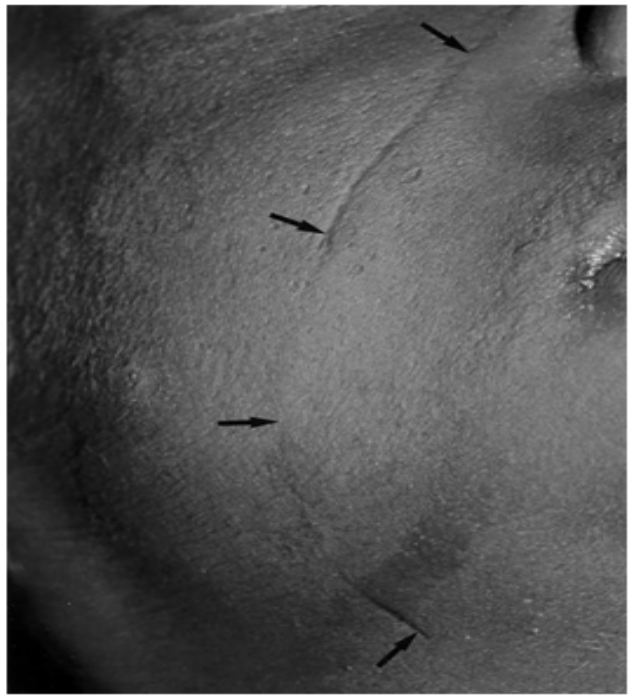

Figure 1: Courtesy of R.W. Byard [22].

In case of suspected poisoning by volatiles or gas, an air sample should be collected directly on the scene, for example using an aerosol container, or other means [23]. 


\section{International Journal of Forensic Sciences}

Finally, also the presence of dark purple colored hypostasis may suggest VSRD [24].

\section{VSRD: Autopsy and Histological Findings}

Forensic pathologists should always consider whether volatile substances have been involved in sudden and unexpected deaths, particularly with respect to young adults (the age group in which VSA occurs more frequently).

In general, the autopsy performed on children and young adults investigates potential cardiovascular diseases, as the fatal outcome associated with them is often the first clinical manifestation in apparently healthy subjects. Nevertheless, a careful autopsy may become a diagnostic tool also for VSRDs, as it can exclude any morphological findings of juvenile sudden cardiac deaths.

Further, dilated cardiomyopathy has been described in chronic abusers and myocardial infarction (without signs of coronary atherosclerosis and / or myocarditis [25-28]) has been observed in subjects who assumed volatile substances just before clinical presentation of acute ischemia [29]. Therefore, the heart autopsy should be conducted in a thorough way, integrated by complete toxicological analysis, even when morphological findings of juvenile sudden cardiac deaths are present $[30,31]$.

Unfortunately, in many cases the post-mortem features of VSRDs may be minimal and non- specific, like venous congestion, fatty change of the liver and marked pulmonary edema. Internal features that may be present include a mild tracheitis and/or bronchitis, due to the recurrent flowing of the volatile substance in the airways. These findings, however, have no conclusive value in the diagnosis of a VRD [32].

Cardiac and pulmonary histological findings are of greater interest for their pathological significance. In juvenile sudden death without coronaropathy or markers of myocarditis, a myocardial fibrosis could be found as a product of cardiac remodeling following repeated hypoxic events connected to chronic butane-gas assumption. In fact, the fibrosis occurs as a response to tissue damage, when the heart try reparation phenomena in order to preserve its structure and function [33].

Inside lungs, the development of an obstructive microangiopathy with vesicular transformation of capillary endothelium, and the presence of "blebs" in the alveolar wall capillaries, may be caused to the direct toxic effect of the volatile substance's chronic assumption, as this blocks the microcirculation and cause pulmonary hypertension (Figure
2). The swelling of the basal membrane - produced by the incorporation of the volatile substance into the lipid layer of neuronal cells - could be proposed for the respiratory tract because, after sniffing, the volatile agent first must pass the basal membranes in the alveolar walls [34].

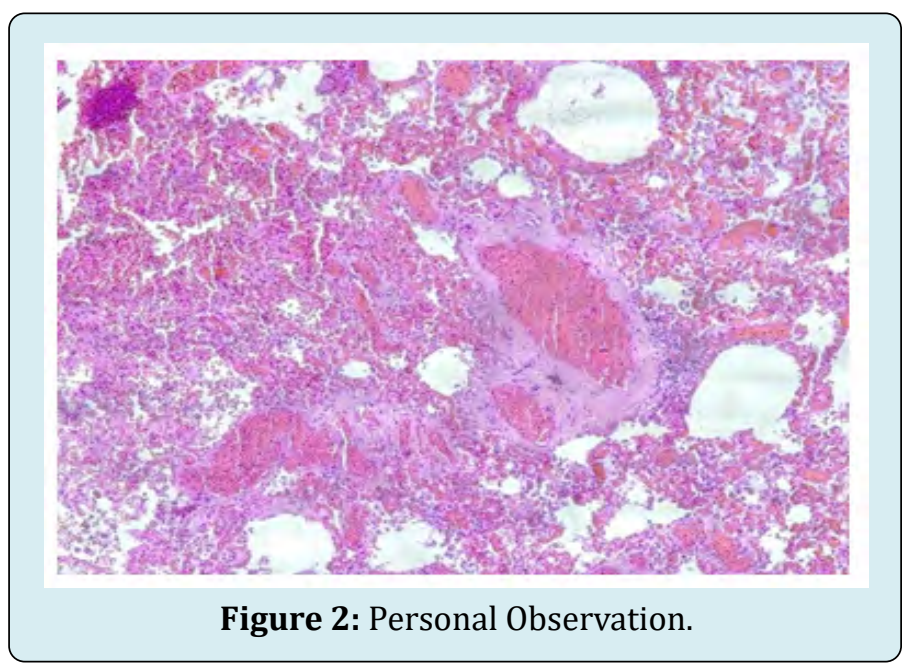

In order to explain the pathogenesis of VSRD the myocardial antibodies expression - in fatal cases related to butane intake - has been studied with immunohistochemistry.

Using the markers fibronectin and troponin C, Pfeiffer et al. demonstrated an altered expression in VSRDs of fibronectin and troponin $\mathrm{C}$, in single or groups of myocardial fibers [34]. Large panels of immunohistochemical antigens, which represent variable expressivity depending on the prolongation of the ischemia time, have been used by Novosel, et al. (Desmin, Myoglobin, Fibronectin, Fibrinogen and (C9). The results confirm the depletion of cellular antigens, a process that starts earlier than the deposition of serum antigens [35].

Ventura et al. recently demonstrated an altered expression of fibronectin and troponin $\mathrm{C}$ in the cardiomyocytes in fatal butane poisoning cases, as a marker of diffuse hypoxic myocardial damage, and suggested to conduct also immunohistochemical investigations in VSRDs [36].

\section{VSRD: Mechanism of Death}

The exact mechanism of VSRDs is yet to be determined and it is possible that it would be different depending on the substance taken. Several aspects of the cardiac action potential appear to be affected by halogenated hydrocarbons assumption, while other misused volatile substances probably cause nervous, cardiac and pulmonary toxicity - 


\section{International Journal of Forensic Sciences}

however, there is a lack of research for these mechanisms.

The inhalation of hydrocarbons is suspected to sensitize the myocardium to adrenaline, and the sudden increase of this hormone may cause a fatal arrhythmia - primarily a ventricular fibrillation, immediately after a sudden fear, a muscular exercise or after sexual activity [37]. The mechanism could be a reversible inhibition of the cardiacvoltage-activated sodium channel, as it has been described for toluene in a study using rat myocytes (toluene completely inhibited the fast-inward sodium channel in a reversible manner) [38].

Further, a prolonged QT dispersion is demonstrated in subject who misused toluene. QT dispersion is a useful risk marker for cardiac arrhythmias and sudden cardiac death and measure the heterogeneity of repolarization time in the ventricular myocardium. This has been widely studied in myocardial infarction, coronary artery disease, long QT syndrome, hypertrophic cardiomyopathy, and chronic heart failure, as a predictor of fatal arrhythmias and sudden cardiac death [39].

Both symptomatic (defined as recent syncope in chronic users) and asymptomatic toluene abusers have an increased QT dispersion; this sign was greater in symptomatic than asymptomatic subjects [40]. The most likely mechanism of increased QT duration and dispersion is the inhibition of the human ether-a-go-go related gene (hERG), otherwise known as the delayed rectifier potassium channel (IKr). Chloroform has also been shown to inhibit the $\mathrm{IKr}$ and other volatile substances which are likely to share this feature [41].

The lipophilic narcotic agents can cause damage of basal membranes in neuronal cells, due to the incorporation of the agent into the lipid layer, which may result in swelling of the basal membrane cells. This happens because of the lipophilic features of butane which is easily distributed by blood in brain as well as in other organs involved in metabolism such as liver and kidneys. This high lipid solubility is demonstrated by the high amount of volatile substance in the brain, when this is determined during toxicological investigations $[17,42]$.

Finally, in suicides the exposure to high volume of the employed gas (usually butane in gas cylinder) determines suffocation secondary to lack of oxygen for its displacement by asphyxiating gas in the breathable environment [43].

\section{VSRD: How about Toxicological Sampling?}

Collection, storage and pre-analytical handling of samples from autopsy are highly critical considering the natural evaporation of volatile substance. Despite studies conducted on toxicological sampling, the collection and preservation of volatile substances in forensic context is still a matter of debate. There are several papers describing materials and procedures for volatile substance sampling during the autopsy. Ideally, samples should be collected in pre-weighted, gas-tight, well-sealed HS vials with minimal headspace. For fluids and tissues sampling, general recommendations and specific procedures for volatile substances can be found in worldwide forensic texts and/or from forensic toxicological guidelines [44-50].

More specifically:

a) Samples should be collected immediately after opening thoracic and abdominal cavities and put directly into the device (gastight syringe or other) in which the analysis is carried out. Devices other than syringes should be made of glass. Nevertheless, qualitative results obtained by sampling with a plastic syringe (sealed with Teflon $₫$, Parafilm $®$ or aluminum) can be helpful when gastight syringes are not available [17];

b) In general, samples from tissues without preservative should be added; brain must always be taken in case of suspected VSRDs, above all if the autopsy is performed late after death. In postmortem period, blood concentration could decrease due to evaporation, while the brain is a good tissue to examine, and volatiles will be detected for longer than in many other sample $[51,52]$;

c) Volatile substances are stored in fatty tissues that may be a good matrix for postmortem analysis [53]; the specimen (ca. $2 \times 2 \times 1 \mathrm{~cm}^{3}$ ) can be taken from the subcutaneous adipose tissue of the abdominal wall, immediately after opening the cavity (see Figure 3);

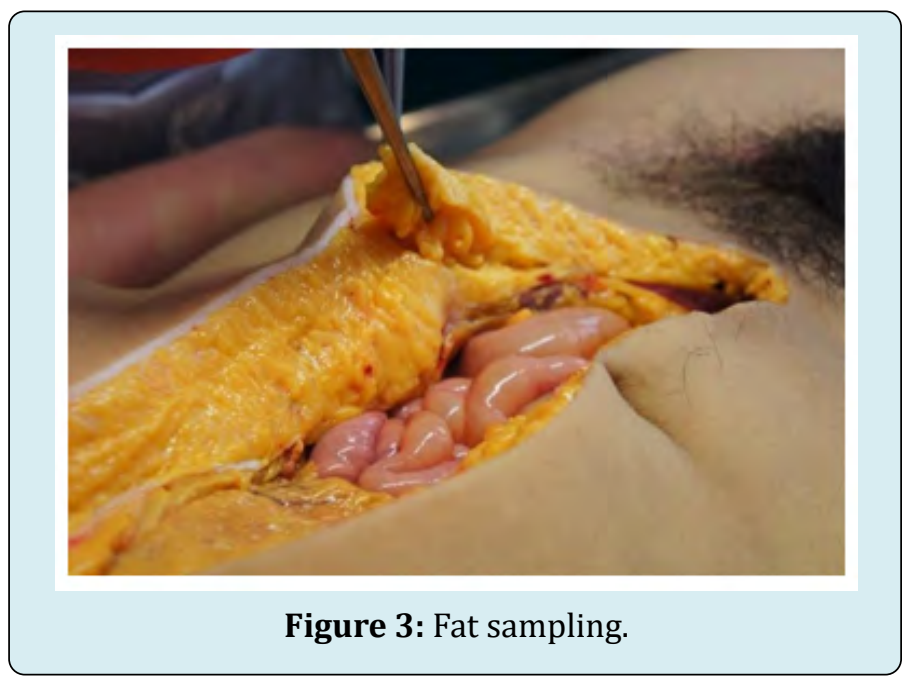

d) If the suspicion of a VSRD is consistent from the beginning of the autopsy, it is necessary to use gastight syringes and carry out the sampling in the lumen of the vessel intact; central blood can be taken from the right atrium, inferior vena cava or another large vessel in mediastinum; the 


\section{International Journal of Forensic Sciences}

peripheral blood can be sampled from the femoral vessels in the "Scarpa's triangle". To avoid contamination, this choice is better than take a specimen from the iliac vessels in the abdominal cavity;

e) The container should be as full as possible to minimize headspace; immediately after the autopsy, and before sealing devices, an internal standard addition will minimize evaporation when the analytical procedure is performed [54]; the top of containers must be sealed with Teflon $\AA$, Parafilm $\AA$ or aluminum;

f) Is essential to transmit the samples to the forensic toxicologist immediately; blood samples stored at $+4{ }^{\circ} \mathrm{C}$ for 3 days lose up to $50 \%$ of the initial concentration; butane disappeared totally after being stored 14 days in the same conditions [55];

g) Direct sampling of the air from the lungs is important; however, the concentration can be altered if a cardiopulmonary resuscitation (CPR) was performed; CPR and the other life support procedures (mechanical ventilation and oxygen administration) may blow off most of the volatile substance from the respiratory tract. During the autopsy for sampling the air in the respiratory tract, a lung should be withdrawn in toto, after ligature of the main bronchus, section of the hilum and put it into a glass container. The sample is then taken in the forensic laboratory; in this process if plastic (instead of glass) containers are used, one should expect a greater dispersion of volatile substances [56].

The specimen of the air from the respiratory tract can be made also in situ, limiting contamination. After having exposed the larynx and the trachea in situ, the upper respiratory tract must be prepared without manipulating it. The sample is then taken from one the main bronchus, ensuring anatomical continuity - see Figure 4 [17].

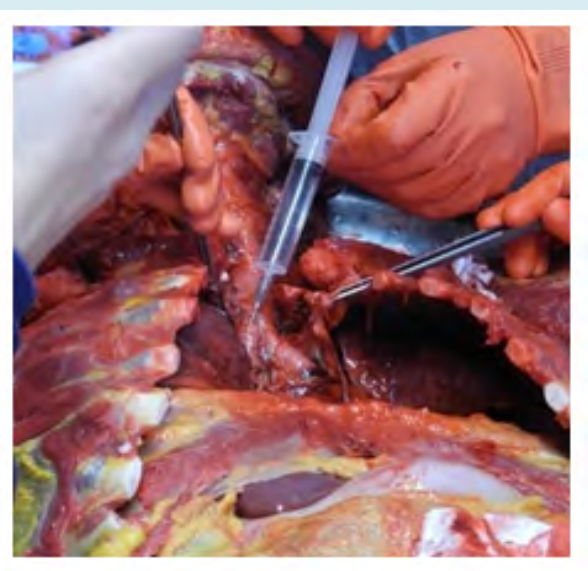

Figure 4: In situ air sampling.

\section{Conclusion}

In sudden deaths, forensic pathologist should always consider the possibility that volatile substances are involved, particularly with respect to sudden deaths of adolescents and young adults. Physical evidence of a prolonged abuse may be found in the form of "glue sniffer's rash" and semicircular impression on the skin of the perioral zone. However, the absence of such evidence should not be considered an exclusion criterion of VRSDs.

Crime scene investigation may provide useful information about the presence of volatile substances and objects which may be found on the hands of the subject or near the body. In cases where poisoning by volatile substances is suspected, a specimen should be collected directly on the scene, because the collection, storage and pre-analytical handling of samples from the autopsy are highly critical due to the natural evaporation of the substance. Samples should be collected immediately and put directly into the device (gastight syringe or other) in which the analysis is carried out.

When performing the autopsy, central blood can be taken from the right atrium, inferior vena cava or another large vessel in mediastinum. The peripheral blood can be sampled from the femoral vessels in the "Scarpa's triangle". It is appropriate to use gastight syringes and carry out the sampling in the lumen of the vessel intact to avoid contamination. Nevertheless, qualitative results obtained by sampling with a plastic syringe (sealed with Teflon', Parafilm or aluminum) can be helpful when gas-tight syringe are not available.

As blood concentration in postmortem period could decrease for evaporation, brain must always be taken because, if the autopsy is performed long after the death, the volatiles could be detected in this tissue for longer than in many other samples. Samples of fatty tissue can be taken from the adipose subcutaneous tissue of the abdominal wall, immediately after opening the cavity - any storage container should be as full as possible to minimize headspace.

During the autopsy, to sample the air in the respiratory tract, a lung should be withdrawn in toto, after ligature of the main bronchus, section of the hilum and put it into a glass container. The specimen of the air from the respiratory tract can also be made in situ, limiting contamination. After having exposed the larynx and the trachea in situ, the upper respiratory tract must be prepared without manipulating it. The sample is then taken from one the main bronchus, ensuring anatomical continuity Therefore, in light of the conclusions presented in this paper, when VSRDs are suspected, the forensic pathologist should be as careful 


\section{International Journal of Forensic Sciences}

as possible, beginning with the crime scene investigation to the post-mortem analysis. Only in this way one can minimize both the number of unrecognized VSRDs and the misunderstandings between sudden deaths and VSRDs.

\section{References}

1. Bass M (1970) Sudden sniffing death. J Am Med Assoc 212(12): 2075-2079.

2. Tsoukali H, Dimitriou A, Vassiliades N (1998) Death during deliberate propane inhalation. Forensic Sci Int 93(1): 1-4.

3. Rohring T (1997) Sudden death due to butane inhalation. Am J Forensic Med Pathol 18(3): 299-302.

4. Ago M, Ago K, Ogata M (2002) A fatal case of n-butane poisoning after inhaling anti-perspiration aerosol deodorant. Leg Med 4(2): 113-118.

5. Tanaka N, Kinoshita H, Jamal M, Kumihashi M, Tsutsui K, et al. (2012) An autopsy case of fuel gas abuse. Rom J Leg Med 20: 195-196.

6. Sironi L, Adamasi A, Zoja R (2016) Recreational inhalation of butane and propane in adolescents: Two forensic cases of accidental death. Forensic Sci Int 266: e52-e58.

7. (2020) Volatile substances drug profile. European Monitoring Centre for Drugs and Drug Addiction.

8. Wyse DG (1973) Deliberate inhalation of volatile hydrocarbons: a review. Can Med Assoc J 108(1): 71-74.

9. Phatak DR, Walterscheid J (2012) Huffing air conditioner fluid: a cool way to die? Am J Forensic Med Pathol 33(1): 64-67.

10. (2018) Deaths related to volatile substances and helium in Great Britain: 2001 to 2016 registration. Office for National Statistics.

11. Anderson CE, Loomis GA (2003) Recognition and prevention of inhalant abuse. Am Fam Physician 68(5): 869-874.

12. Ford JB, Sutter ME, Owen KP, Albertson TE (2014) Volatile Substance Misuse: An Updated Review of Toxicity and Treatment. Clinic Rev Allerg Immunol 46(1): 19-33.

13. Murty OP (2008) Plastic bag asphyxia with LPG (butanepropane) inhalation-Fatal Asphyxiphilia or Suicide? J Indian Acad Forensic Med 30(4): 216-222.

14. McLennan JJ, Sekula Perlman A, Lippstone MB, Callery
RT (1998) Propane-associated autoerotic fatalities. Am J Forensic Med Pathol 19(4): 381-386.

15. Cordner SM (1983) An unusual case of sudden death associated with masturbation. Med Sci Law 23(1): 5456.

16. Jackowski C, Romhild W, Aebi B, Bernhard W, Krause D, et al. (2005) Autoerotic accident by inhalation of propane-butane gas mixture. Am J Forensic Med Pathol 26(4): 355-359.

17. Romolo FS, di Luca NM, Ciallella C, Bottoni E, Fiore PA, et al. (2017) Volatile lipophilic substances management in case of fatal sniffing. J of Forensic Leg Med 52: 35-39.

18. Gioia S, Lancia M, Bacci M, Suadoni F (2015) A fatal case of acute butane-propane poisoning in a prisoner under psychiatric treatment. Am J Forensic Med Pathol 36(4): 251-253.

19. Rossi R, Suadoni F, Pieroni L, De Giorgio F, Lancia M (2012) Two cases of acute propane/butane poisoning in prison. J Forensic Sci 57(3): 832-834.

20. Wick JR, Gilbert D, Felgate P, Byard R (2007) Inhalant Deaths in South Australia: a 20 - year retrospective autopsy study. Am J of Forensic Med and Path 28(4): 319-322.

21. Watson JM (1978) Clinical and laboratory investigations in 132 cases of solvent abuse. Med Sci Law 18(1): 40-43.

22. Byard RW, Chivell WC, Gilbert JD (2003) Unusual facial markings and lethal mechanisms in a series of gasoline inhalation deaths. Am J Forensic Med Pathol 24(3): 298302.

23. Skopp G (2010) Postmortem toxicology. Forensic Sci Med Pathol 6(4): 314-325.

24. Fukunaga T, Yamamoto $H$, Tanegashima A, Yamamoto $Y$, Nishi K (1996) Liquefied petroleum gas (LPG) poisoning: report of two cases and review of the literature. Forensic Sci Int 82(3): 193-200.

25. Vural M, Ogel K (2006) Dilated cardiomyopathy associated with toluene abuse. Cardiology 105(3): 158161.

26. Samson R, Kado H, Chapman D (2012) Huffing-induced cardiomyopathy: a case report. Cardiovasc Toxicol 12(1): 90-92.

27. Bruga A, Das $T$ (2019) Postmortem Diagnosis of Myocardial Infarction Due to Butane Gas Intoxication in a Child A Case Report. Am J Forensic Med Pathol 40(1): 


\section{International Journal of Forensic Sciences}

81-83.

28. Amadasi A, Mastroluca L, Marasciuolo L, Caligara M, Sironi L, et al. (2015) Death due to acute tetrachloroethylene intoxication in a cronic abuser. Int J Legal Med 129(3): 487-493.

29. El Menyar AA, El Tawil M, Al Suwaidi J (2005) A teenager with angiographically normal epicardial coronary arteries and acute myocardial infarction after butane inhalation. Eur J Emerg Med 12(3): 137-141.

30. Di Gioia CR, Autore C, Romeo DM, Ciallella C, Aromatario MR, et al. (2006) Sudden Cardiac death in younger adults: autopsy diagnosis as a tool for preventive medicine. Hum Path 37(7): 794-801.

31. Di Gioia CR, Giordano C, Cerbelli B, Pisano A, Perli E, et al. (2016) Nonischemic left ventricular scar and cardiac sudden death in the young. Hum Path 58: 78-89.

32. Garriot J, Petty CS (1980) Death from inhalant abuse: toxicological and pathological evaluation of 34 cases. Clin Toxicol 16(3): 305-315.

33. Swynghedauw B (1999) Molecular mechanisms of myocardial remodeling. Physiol Rev 79(1): 215-262.

34. Pfeiffer H, Al Khaddam M, Brinkmann B, Kohler H, Beike J (2006) Sudden death after isobutane sniffing: a report of two forensic cases. Int J Leg Med 120(3): 168-173.

35. Novosel I, Kovacic Z, Gusic S, Batelja L, Nestic M, et al. (2011) Immunohistochemical detection of early myocardial damage in two sudden deaths due to intentional butane inhalation. Two case reports with review of literature. J Leg Med 18(3): 125-131.

36. Ventura F, Barranco R, Landolfa MC, Gallo M, Gianelli Castiglione A, et al. (2017) Fatal poisoning by butane sniffing: A forensic analysis and immunohistochemical detection of myocardial hypoxic damage. J Forensic Leg Med 51: 57-62.

37. Gunn J, Wilson J, Mackintosh AF (1989) Butane sniffing causing ventricular fibrillation. Lancet 333(8638): 617.

38. Cruz SL, Orta Salazar G, Gauthereau MY, Millan Perez Pena L, Salinas Stefanon EM (2003) Inhibition of cardiac sodium currents by toluene exposure. $\mathrm{Br} \mathrm{J}$ Pharmacol 140(4): 653-660.

39. Malik M, Batcharov VN (2000) Measurement, Interpretation and Clinical Potential of QT Dispersion. J Am Coll Cardiol 36(6): 1749-1766.

40. Alper AT, Akyol A, Hasdemir H, Nurkalem Z, Guler O, et al. (2008) Glue (toluene) abuse: increased QT dispersion and relation with unexplained syncope. Inhal Toxicol 20(1): 37-41.

41. Himmel HM (2008) Mechanisms involved in cardiac sensitization by volatile anesthetics: general applicability to halogenated hydrocarbons? Crit Rev Toxicol 38(9): 773-803.

42. Djurendic Brenesel M, Stojiljkovic G, Pilija V (2016) Fatal Intoxication with Toluene Due to Inhalation of Glue. J Forensic Sci 61(3): 875-878.

43. Bowen SE, Daniel J, Balster RL (1999) Deaths associated with inhalant abuse in Virginia from 1987 to 1996. Drug Alcohol Depend 53(3): 239-245.

44. Skopp G (2004) Preanalytic aspects in postmortem toxicology. Forensic Sci Int 142(2-3): 75-100.

45. El Balkhi S, Coutaz Fluck C, Moreau F, Paraf FF, Gaulier J (2006) Is it worth carrying out determination of $\mathrm{N}$-butane in postmortem samples? A case report and a comprehensive review of the literature. Int J Legal Med 130(5): 1223-1229.

46. Saukko P, Knight B (2016) Knight's Forensic Pathology, 4th (edn.), CRC Press Taylor \& Francis Group.

47. Flanagan RJ (2011) Volatile Substances In: Clarke's Analysis of Drugs and Poisons, Moffat AC, Osselton MD, Widdop B, Pharmaceutical Press ???: London, pp: 230242.

48. (2020) TIAFT The International Association of Forensic Toxicologists. Committee of Systematic Toxicological Analysis. Recommendations on Sample Collection, TIAFT Bulletin XXIX, 1.

49. Skopp G, Von Meyer L (2020) Guideline for Quality Control in Forensic Toxicological Analyses. GTFCh.

50. Flanagan RJ, Streete PJ, Rampsey JD (1997) Volatile Substance Abuse. Practical guidelines for analytical investigation of suspected cases and interpretation of results.

51. Tranthim Fryer DJ, Hansson RC, Norman KW (2001) Headspace/solid-phase microextraction/gas chromatography-mass spectrometry: a screening technique for the recovery and identification of volatile organic compounds (VOC's) in postmortem blood and viscera samples. J Forensic Sci 46(4): 934-946.

52. Sugie H, Sasaki C, Hashimoto C, Takeshita H, Nagai T, et al. (2004) Three cases of sudden death due to butane or propane gas inhalation: analysis of tissues for gas 


\section{International Journal of Forensic Sciences}

components. Forensic Sci Int 143(2-3): 211-214.

53. Wille SMR, Lambert WEE (2004) Volatile substance abuse-postmortem diagnosis. Forensic Sci Int 142(23): 135-156.

54. Seto Y (1994) Determination of volatile substances in biological samples by headspace gas chromatography. J Chromatogr A 674(1-2): 25-62.
55. Fuke C, Miyazaki T, Arao T, Morinaga Y, Takaesu H, et al. (2002) A fatal case considered to be due to cardiac arrhythmia associated with butane inhalation. Leg Med (Tokyo) 4(2): 134-138.

56. Dinis Oliveira RJ, Vieira DN, Magalhães T (2016) Guidelines for Collection of Biological Samples for Clinical and Forensic Toxicological Analysis. Forensic Sci Res 1(1): 42-51. 